\title{
Identification of different origins for s- shaped current voltage characteristics in planar heterojunction organic solar cells
}

Cite as: J. Appl. Phys. 111, 054509 (2012); https://doi.org/10.1063/1.3692050

Submitted: 07 December 2011 . Accepted: 02 February 2012 . Published Online: 08 March 2012

Julia Wagner, Mark Gruber, Andreas Wilke, Yuya Tanaka, Katharina Topczak, Andreas Steindamm, Ulrich Hörmann, Andreas Opitz, Yasuo Nakayama, Hisao Ishii, Jens Pflaum, Norbert Koch, and Wolfgang Brütting

ARTICLES YOU MAY BE INTERESTED IN

Imbalanced mobilities causing S-shaped IV curves in planar heterojunction organic solar cells Applied Physics Letters 98, 063301 (2011); https://doi.org/10.1063/1.3553764

Dipole induced anomalous S-shape $I-V$ curves in polymer solar cells Journal of Applied Physics 105, 094512 (2009); https://doi.org/10.1063/1.3117513

Two-layer organic photovoltaic cell

Applied Physics Letters 48, 183 (1986); https://doi.org/10.1063/1.96937 


\title{
Identification of different origins for s-shaped current voltage characteristics in planar heterojunction organic solar cells
}

\author{
Julia Wagner, ${ }^{1, \text { a) }}$ Mark Gruber, ${ }^{1}$ Andreas Wilke, ${ }^{2}$ Yuya Tanaka, ${ }^{3}$ Katharina Topczak, ${ }^{4}$ \\ Andreas Steindamm, ${ }^{4}$ Ulrich Hörmann, ${ }^{1}$ Andreas Opitz, ${ }^{2}$ Yasuo Nakayama, ${ }^{5}$ \\ Hisao Ishii, ${ }^{3,5}$ Jens Pflaum, ${ }^{4}$ Norbert Koch, ${ }^{2}$ and Wolfgang Brütting ${ }^{1, b)}$ \\ ${ }^{1}$ Institute of Physics, University of Augsburg, 86135 Augsburg, Germany \\ ${ }^{2}$ Institute of Physics, Humboldt University of Berlin, 12489 Berlin, Germany \\ ${ }^{3}$ Graduate School of Advanced Integration Science, Chiba University, Chiba 263-8522, Japan \\ ${ }^{4}$ Institute of Physics, University of Würzburg and ZAE Bayern, 97074 Würzburg, Germany \\ ${ }^{5}$ Center for Frontier Science, Chiba University, Chiba 263-8522, Japan
}

(Received 7 December 2011; accepted 2 February 2012; published online 8 March 2012)

\begin{abstract}
We investigate different parameters influencing the occurrence of s-shaped current voltage $(j-V)$ characteristics in planar heterojunction organic solar cells. It is shown how substrate modification, purity of the active organic material as well as variation of the top contact can affect the shape of the $j-V$ curves. The studies are performed on vacuum-evaporated planar heterojunction solar cells with diindenoperylene (DIP) as electron donor and fullerene $\mathrm{C}_{60}$ as acceptor. The focus is on the fill factor and forward current being the most direct indicators for s-shapes in $j$ - $V$ curves. We find that the main effect of substrate heating during film growth can be assigned to changes in energy barriers rather than to the modification of morphology and crystallinity, which is also influenced by elevated substrate temperatures. The decisive role of the barrier height between the anode work function and the HOMO (i.e., highest occupied molecular orbital) level of the donor is approved by comparing hole-injection layers with different work functions. By using donor materials of different purity we find a correlation between charge carrier mobilities and fill factors. Finally, it is demonstrated that an exciton blocking interlayer is essential to get high fill factors when aluminum is used as top contact, but is dispensable for samarium as cathode material. This finding can be ascribed to the protective effect of the interlayer from aluminum diffusion into the active semiconductor rather than to its role as exciton diffusion barrier. (C) 2012 American Institute of Physics. [http://dx.doi.org/10.1063/1.3692050]
\end{abstract}

\section{INTRODUCTION}

Since the early beginnings of the research on organic photovoltaics in the 1970s, ${ }^{1}$ the performance of the solar cells could be continuously improved, most importantly by the introduction of the donor-acceptor heterojunction concept. $^{2}$ Nowadays record power-conversion efficiencies of up to $10 \%$ are achieved in single-junction as well as in tandem cells, ${ }^{3}$ bringing them close to commercialization.

With the help of innovative organic semiconductors high open circuit voltages $\left(V_{\text {oc }}\right)$ can be obtained ${ }^{4-8}$ and optimized light harvesting is realized by applying infrared absorbers. ${ }^{9,10}$ However, current voltage characteristics are frequently affected by an undesirable s-shape behavior, i.e., they show a decrease of the current close to $V_{\mathrm{oc}}$ and in forward direction of the diode. This effect can severely reduce the fill factor (FF) and hence the efficiency of the solar cell.

Recently, different aspects being responsible for the appearance of that undesired feature have been proposed. In most of the cases the s-kink is attributed to energy barriers at the contacts, ${ }^{11-16}$ whereas the formation of these interface barriers might have different origins. Comparing driftdiffusion simulations with experimental results Tress et al.

\footnotetext{
${ }^{\text {a)} E l e c t r o n i c ~ m a i l: ~ j u l i a . w a g n e r @ p h y s i k . u n i-a u g s b u r g . d e . ~}$

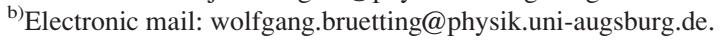

emphasize the crucial role of injection barriers between the hole-transport layer and the donor material both in planar (PHJ) and bulk heterojunction (BHJ) devices. ${ }^{14}$ They show that increasing barrier heights lead to s-shaped $j$ - $V$ curves with low forward currents in the case of PHJ devices, which manifests in severely reduced FFs. Gupta et al. ascribe the concavity of their $j-V$ curves to charge accumulation at the interface between the electrode and the active organic film resulting from incomplete cathode metal coverage or chemical defects at the interface. ${ }^{15}$ Other authors report on s-shapes caused by thermally degraded PEDOT:PSS or oxidized $\mathrm{Ca}$ cathode leading to low conductivity and high series resistance. ${ }^{16}$ Besides interface barriers, factors like morphology and thickness of the active layers can influence the curvature of the $j$-V curves of solar cell devices. ${ }^{17}$ In addition to that, the effect of charge carrier mobility on fill factor was demonstrated in various studies. ${ }^{18-20}$

Here, we present a comprehensive study of different aspects influencing the shape of the $j$ - $V$ curves of molecular semiconductor PHJ cells. All studies are based on the donoracceptor material combination of diindenoperylene (DIP) and $\mathrm{C}_{60}$. DIP has been shown to exhibit an almost balanced transport of electrons and holes along the $c^{\prime}$ direction in single crystals $^{21}$ and thin films, ${ }^{22}$ and remarkably high exciton diffusion lengths of up to $100 \mathrm{~nm} .^{23}$ It was further reported that DIP exhibits exceptionally high structural order in evaporated 
thin films grown on inert substrates, with molecules standing almost upright with their long axis aligned with an angle of about $17^{\circ}$ to the surface normal. ${ }^{24,25}$ Concerning its application as donor in organic solar cells, the main advantage of DIP can be found in its high ionization potential and the favorable energy level alignment with the acceptor $\mathrm{C}_{60}$ leading to high open circuit voltages of up to $0.93 \mathrm{~V}$ as well as its good transport properties resulting in fill factors exceeding $70 \% .{ }^{26}$ Moreover, DIP was also successfully employed as molecular acceptor material in organic solar cells. ${ }^{8}$ It was shown that planar heterojunctions of thiophene derivatives and DIP yield extraordinarily high open circuit voltages of approximately $1.2 \mathrm{~V}$ for poly(3-hexylthiophene) and almost $1.4 \mathrm{~V}$ for heattreated $\alpha$-sexithiophene. ${ }^{8}$

The aim of our work is to elucidate the interplay of different factors influencing the s-shape in a simple PHJ device stack. The effects of substrate modification, purity of the active material as well as top contact variation were studied independently of each other. Substrate modification was realized by thermal treatment and the usage of different hole injection materials, both influencing the energy barrier between the Fermi level of the anode and the HOMO of the donor. The influence of material purity is investigated by comparing different DIP source batches. In addition to their application in the solar cell stack, two batches were comparatively studied in organic field-effect transistors and analyzed by mass spectrometry to figure out the differences in material properties.

Finally, we investigate the influence of $\mathrm{Sm}$ and $\mathrm{Al}$ as metal top contacts and their interplay with the exciton blocking layer bathocuproine (BCP). Ultraviolet photoelectron spectroscopy (UPS) measurements show that Sm-in contrast to $\mathrm{Al}$ - does not diffuse into the $\mathrm{C}_{60}$ but, in fact, forms a closed film already after a few monolayers. Solar cell characteristics of the used cathode materials with and without an additional layer of BCP reveal the decisive role of BCP as a protective layer from metal diffusion rather than its role as exciton diffusion barrier.

\section{EXPERIMENTAL}

The solar cells were fabricated on commercially available tin-doped indium oxide (ITO)-coated glass substrates (purchased from Thin Film Devices, Inc., Anaheim, CA; sheet resistance $\approx 20 \Omega /$ sq), which were subsequently clea ned in an ultrasonic bath with acetone and isopropanol prior to processing. An oxygen plasma treatment was implemented to improve wettability for the aqueous suspension of the intrinsically conducting polymers used as hole injection layers (HILs). Two different commercially available PEDOT:PSS (poly(3,4-ethylenedioxythiophene):poly(styrenesulfonate)) containing formulations were used-differing in their work functions ${ }^{27}$ : Clevios ${ }^{\mathrm{TM}} \mathrm{P}$ AI4083 (designated as PEDOT:PSS, work function $\Phi \approx 5.0-5.2$ (Ref. 28 ) and Clevios $^{\text {TM }}$ HIL1.3 (designated as HIL1.3, work function $\Phi$ $\approx 5.4-5.9$ (Ref. 28) (both purchased from Heraeus Clevios $\mathrm{GmbH}$, Leverkusen, Germany). The polymers were deposited via spin coating and annealed at $125^{\circ} \mathrm{C}$ for $45 \mathrm{~min}$ under ambient conditions. The organic donor material DIP was purchased from two different suppliers (S. Hirschmann, Univ. Stuttgart, Germany and W. Schmidt, Institut für PAH Forschung, Germany) and twice purified by gradient sublimation, just like $\mathrm{C}_{60}$ (purchased from Creaphys, Germany). For some solar cells, a $5 \mathrm{~nm}$ thick layer of bathocuproine (BCP, purchased from Sigma Aldrich, used without further purification) was used as interlayer between $\mathrm{C}_{60}$ and the cathode. The chemical structures of the organic semiconductors are depicted in Fig. 1(a). The metal cathodes of the solar cells (either $100 \mathrm{~nm}$ of $\mathrm{Al}$ or $20 \mathrm{~nm}$ of Sm protected by $80 \mathrm{~nm}$ of $\mathrm{Al}$ ) were evaporated through a shadow mask resulting in solar cells with an active area of $4 \mathrm{~mm}^{2}$. The organic layers as well as the metallic cathode were prepared by thermal evaporation at base pressures of $10^{-6}-10^{-7}$ mbar. The schematic layout of the device stack is shown in Fig. 1(b). Thicknesses of organic and metal films are in situ monitored by quartz microbalances and determined with an accuracy of approximately $\pm 2 \mathrm{~nm}$. Current voltage characteristics of the solar cells are recorded using a source measure unit (Keithley $236 \mathrm{SMU}$ ) in dark and under white light illumination with a white LED (Luxeon LXHL-NWE8) at an intensity of approx. $54 \mathrm{~mW} / \mathrm{cm}^{2}$. As the illumination conditions do not fulfill the AM1.5 G standards, values for power conversion efficiencies are not specified. ${ }^{29}$ Instead, emphasis is placed on the comparability of the samples prepared within one series, i.e., if possible, samples which are compared to each (a)

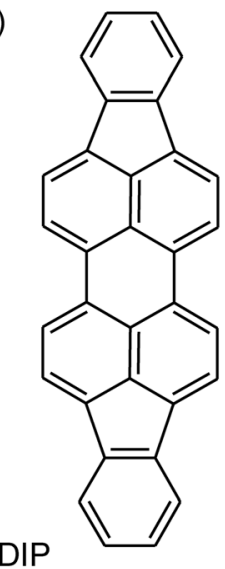

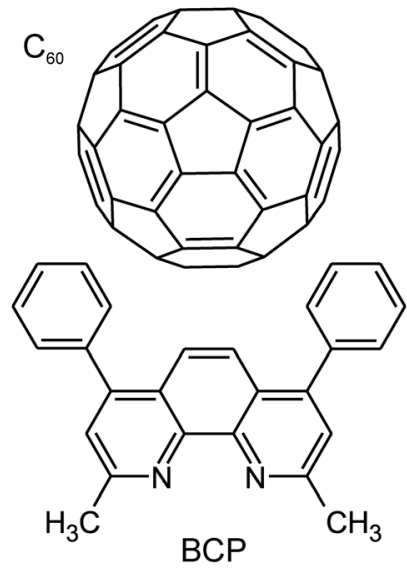

(b)

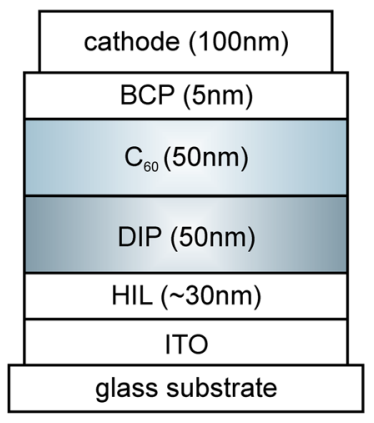

(c)

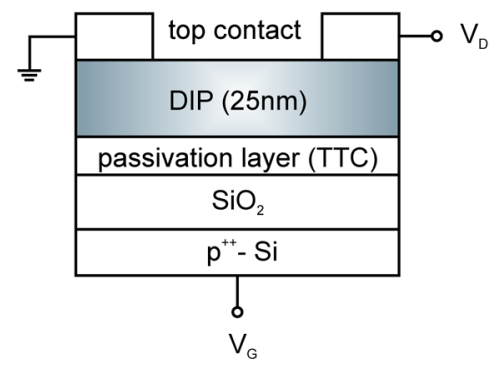

FIG. 1. (Color online) (a) Chemical structure of DIP, $\mathrm{C}_{60}$, and BCP; schematic layout of the PHJ solar cells (b); and top-contact OFETs (c). 
other, were fabricated within one evaporation run under identical conditions and material source batches. The entire cell preparation as well as the electrical measurements was performed without air exposure; i.e., under inert gas atmosphere or in vacuum. Morphological characterization was performed using an atomic force microscope (AFM, Thermo Microscopes Autoprobe CP-Research) under ambient conditions.

Thin-film transistors were prepared on highly doped silicon wafers with $320 \mathrm{~nm}$ thermally grown oxide. A sketch of the OFET layout can be seen in Fig. 1(c). An additional layer of the insulating alkane tetratetracontane (TTC, $\mathrm{C}_{44} \mathrm{H}_{90}, 10$ $\mathrm{nm}$ ) was used as a passivation layer. ${ }^{22,30}$ TTC was purchased from Sigma Aldrich and was used without any further purification. To realize unipolar electron and hole transport, top contacts of Ca and TTF-TCNQ (tetracyanoquinodimethanetetrathiafulvalene) are used, respectively. Source and drain contacts were evaporated through a shadow mask with various channel lengths in the range of $50 \mu \mathrm{m}$ to $150 \mu \mathrm{m}$. In the OFETs we used a $25 \mathrm{~nm}$ thick layer of DIP deposited on top of the passivated substrates. For detailed preparation conditions see Ref. 31. Transistor characteristics were measured using a Keithley 4200 Semiconductor Parameter Analyzer.

Mass spectrometry measurements on different DIP batches were performed using a Finnigan MAT 90 (mass resolution $<0.1$ ).

UPS measurements were performed at two different facilities: Measurements concerning the study of the influence of PEDOT:PSS heating during DIP evaporation were obtained at beamline BL8B of the Ultraviolet Synchrotron Orbital Radiation facility (UVSOR) of the Institute for Molecular Science (IMS), Okazaki, Japan. Spectra were recorded with a hemispherical energy analyzer (VG, ARUPS 10) with $40 \mathrm{eV}$ photon energy. The secondary electron cutoff (SECO) was recorded with the sample biased at $-12 \mathrm{~V}$ to clear the analyzer work function. Sample transfer between preparation chamber (base pressure $1 \times 10^{-7}$ mbar) and analysis chamber (base pressure $4.5 \times 10^{-10} \mathrm{mbar}$ ) was done without breaking UHV conditions. UPS spectra for the influence of top contact modification were recorded using a helium discharge lamp producing fixed excitation energy of $21.22 \mathrm{eV}$ (He I) and a Phoibos 100 hemispherical energy analyzer. The secondary electron cutoffs were measured with the sample biased at $-10 \mathrm{~V}$. Sample preparation for UPS experiments was carried out under conditions comparative to those for the fabrication of solar cells.

\section{EXPERIMENTAL RESULTS}

\section{A. General properties of $j-V$ characteristics}

In this study, the analysis of the solar cell characteristics mainly focuses on their s-shaped behavior, i.e., the reduction of current close to the open-circuit voltage, which reduces the fill factor in the device. As mentioned above, these s-shapes are commonly ascribed to imbalances in charge carrier mobilities or energetic injection and extraction barriers between the photoactive layer system and the electrodes. To get an evaluable parameter, we analyze the $j$ - $V$ curves with respect to the fill factor and forward current being the most direct indicators for s-shapes. The dark current in an organic solar cell is often modeled using the modified Shockley equation ${ }^{32}$

$$
j=j \mathrm{~s}\left\{\exp \left[\frac{e\left(V-j R_{\mathrm{S}}\right)}{n k T}\right]-1\right\},
$$

where $j_{\mathrm{S}}$ is the reverse-bias saturation current density, $n$ the ideality factor, $e$ the electron charge, $R_{\mathrm{S}}$ a series resistance, $k$ Boltzmann's constant, and $T$ the temperature. This expression was originally applied for analyzing and parameterizing the current voltage characteristics of inorganic $p n$-junction solar cells ${ }^{32}$ and was successfully adapted to organic solar cells. ${ }^{33-36}$ The slope of the $j-V$ characteristics in the exponential regime depends on $j_{\mathrm{S}}$ and $n . R_{\mathrm{S}}$ is mainly attributed to the contact resistance between the electrodes and the semiconductor as well as to the bulk resistance of the active layer. ${ }^{37}$ Its value should be as small as possible to get a sharp rise in the forward current regime. Any parasitic resistance-be it high series or low shunt resistances-will reduce the fill factor and thus the overall device efficiency. ${ }^{38,39}$ In the following, we will make use of the parameter $R_{\mathrm{S}}$ as a characteristic value being connected to the s-shape.

\section{B. Influence of bottom contact}

\section{Influence of substrate heating}

We investigate the effect of substrate heating by comparing PHJ devices with (device A) and without (device B) heating the substrate during DIP deposition. The structure of the investigated cells is ITO/PEDOT:PSS/DIP(50 nm)/ $\mathrm{C}_{60}(50 \mathrm{~nm}) / \mathrm{BCP}(5 \mathrm{~nm}) / \mathrm{Al}(100 \mathrm{~nm})$. In all cases $\mathrm{C}_{60}$ was grown with the underlying DIP film kept at room temperature. The $j-V$ characteristics of the corresponding solar cells are shown in Fig. 2(a). The lower part of the figure depicts the logarithmic plot of the dark $j-V$ characteristics together with the fits to the curves in the forward direction of the diode. The photovoltaic parameters as well as the ideality factors and the series resistances of the cells are summarized in Table I.

While the device with the substrate kept at room temperature during DIP deposition is affected by an s-shape (device B), the substrate heating results in an enhancement of the current in forward direction (device $\mathbf{A}$ ). This is reflected by a decrease in series resistance from $R_{\mathrm{S}}=66 \Omega \mathrm{cm}^{2}$ to $R_{\mathrm{S}}=4 \Omega \mathrm{cm}^{2}$, accompanied by an increase in fill factor from $53 \%$ to $63 \%$.

To investigate the impact of substrate temperature on film morphology, the corresponding AFM measurements of DIP layers evaporated on ITO covered with PEDOT:PSS at similar growth conditions as for the solar cells are shown in Fig. 3. It can be seen, that the crystallinity is strongly influenced by the substrate treatment. Figure 3(a) displays the morphology of $50 \mathrm{~nm}$ DIP evaporated on unheated substrate as determined by AFM. When heating the substrate to $100{ }^{\circ} \mathrm{C}$ during evaporation the surface topography changes from round-shaped islands to a terrace-like structure with extended crystallites (Fig. 3(b)).

This pronounced change in crystallization behavior likely influences the transport properties inside the film. On the other 
(a)

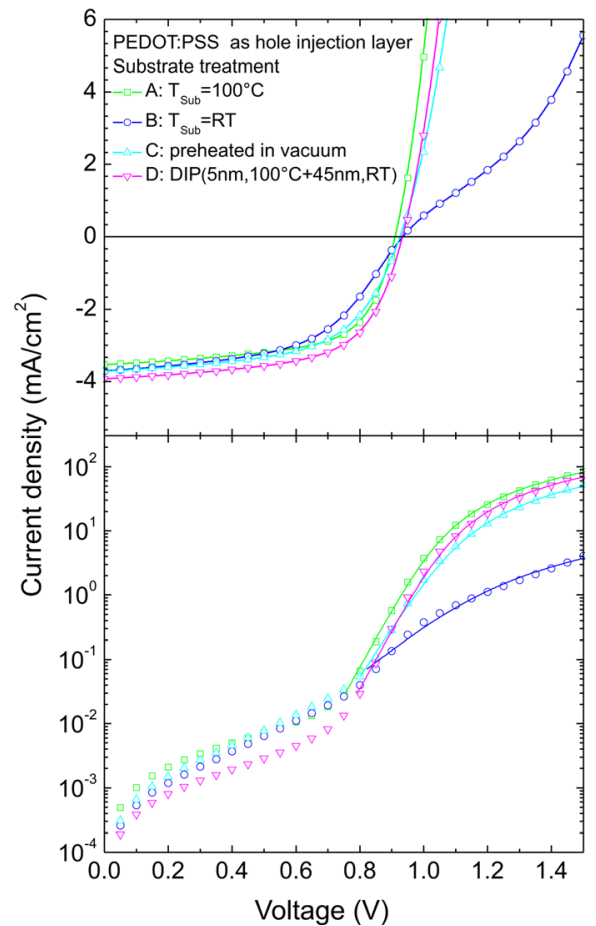

(b)

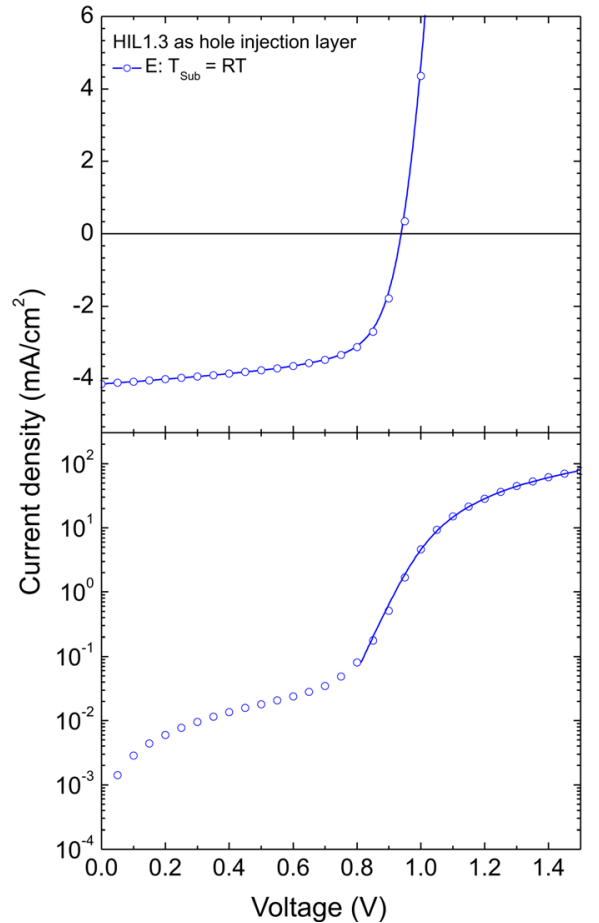

(c)

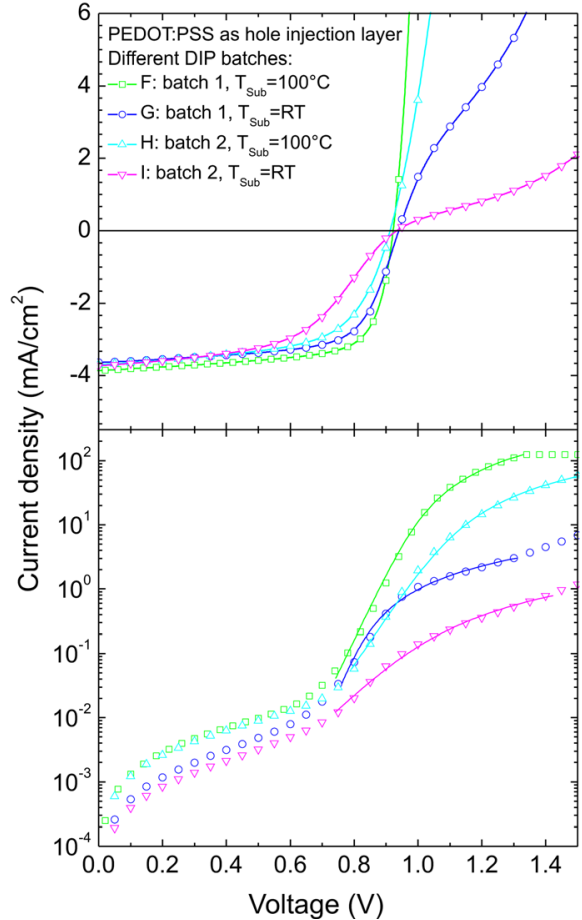

FIG. 2. (Color online) Current voltage characteristics of PHJ solar cells. (a) Devices A-D: ITO/ PEDOT:PSS/ DIP(50 nm)/ $\mathrm{C}_{60}(50 \mathrm{~nm}) / \mathrm{BCP}(5 \mathrm{~nm}) / \mathrm{Al}$ cells with different substrate temperatures during DIP evaporation. (b) Device E: ITO/ HIL1.3/ DIP(50 nm)/ C 60 (50 nm)/ BCP(5 nm)/ Al cell with DIP evaporated at room temperature. (c) Devices F-I: ITO/ PEDOT:PSS/ DIP(50 nm)/ $\mathrm{C}_{60}(50 \mathrm{~nm}) / \mathrm{BCP}(5 \mathrm{~nm}) / \mathrm{Al}$ cells with different DIP source batches. Upper parts: $j-V$ characteristics under white LED illumination. Lower parts: Logarithmic plot of the dark $j$ - $V$ characteristics (open symbols). The solid lines are fits based on the modified diode equation. Results of the fits are given in Table I.

hand, it is well known that annealing of PEDOT:PSS films spun-cast onto ITO leads to an increase of its work function, ${ }^{40}$ which would yield to a lowering of the hole injection barrier from the anode to the HOMO of DIP. Concerning the sshaped characteristics of the solar cells, it is hard to distinguish the role of charge carrier injection at the electrodes and transport inside the DIP film as both might be affected by substrate heating. In order to separate both effects we compare the solar cell characteristics where the anode was heated all the time during DIP evaporation (sample A) or not heated at all (sample B) with a device, where the ITO/PEDOT:PSS was heated to $100{ }^{\circ} \mathrm{C}$ inside the evaporation chamber but was left to cool down to room temperature before DIP growth (sample C). Furthermore, a solar cell was fabricated with the first monolayers $(5 \mathrm{~nm})$ of DIP grown at $100{ }^{\circ} \mathrm{C}$ substrate temperature followed by room temperature growth of the remaining $45 \mathrm{~nm}$ of DIP (sample D). The $j-V$ characteristics of the corresponding solar cells are included in Fig. 2(a). All cells show open circuit voltages slightly above $0.9 \mathrm{~V}$ and almost similar short circuit currents. For devices where the substrate was heated before, during, or partly during the DIP evaporation we find an ideality factor of $n \approx 2-2.5$ and a series resistance of $R_{\mathrm{S}} \approx 4-6 \Omega \mathrm{cm}^{2}$. Only for the completely unheated device (sample B) $R_{\mathrm{S}}$ is increased by a factor of more than 10 , causing the concavity in the $j-V$ curve.

The corresponding AFM images of samples $C$ and D are depicted in Fig. 3. For $5 \mathrm{~nm}$ DIP on heated PEDOT:PSS (Fig. 3(c)), the beginning of terrace growth is visible. Evaporating another $45 \mathrm{~nm}$ DIP-after the substrate has cooled down-leads to a morphology with small islands (Fig. 3(d)) similar to the one without heated underlayer (sample B), showing that the underlying structure is not adapted. For DIP evaporation at room temperature but on a preheated PEDOT:PSS coated ITO-substrate, the topography is similar to that in Fig. 3(a) and thus not explicitly shown here. This is a first hint that the DIP layer morphology and crystallinity are not the primary source of s-shaped $j-V$ characteristics. It rather indicates that the interface between PEDOT:PSS and DIP plays the decisive role.

To assess the energy level alignment between PEDOT:PSS and the donor DIP, thickness dependent UPS investigations on heated and unheated PEDOT:PSS were performed. Figures 4(a) and 4(b) show the UPS spectra of heated (straight lines) and unheated (dashed lines) ITO/PEDOT:PSS covered with DIP (in each case, only the spectra of two different thicknesses are shown for clarity). The PEDOT:PSS/DIP interface energetics are schematically summarized in Figs. 5(a) and 5(b) for the unheated and the heated case, respectively. The initial conducting polymer work function of PEDOT:PSS amounts to $4.75 \mathrm{eV}$ (secondary electron cut-off (SECO) spectra in Fig. 4(a)). For the heated case, the work function is increased from $4.9 \mathrm{eV}$ to $5.1 \mathrm{eV}$ upon annealing. As will be discussed below, the work function of PEDOT:PSS depends critically on the residual water content in the polymer film and is thus extremely sensitive to the precise preparation procedure. Therefore, slightly different storage conditions between substrate preparation and measurement could be responsible for the deviation between the work functions of the unheated PEDOT:PSS films. The valence region spectra (Fig. 4(b)) show that the low binding energy onset of the DIP 
TABLE I. Open circuit voltage $V_{\mathrm{oc}}$, short circuit current density $j_{\mathrm{sc}}$, fill factor FF, series resistance $R_{\mathrm{S}}$, and ideality factor $n$ for solar cells with different hole injection layers (HILs) and substrate treatment during evaporation. Nominally equal samples might differ in their characteristics if not fabricated in the same evaporation run. It has to be mentioned that devices $\mathrm{E}$ and $\mathrm{P}$ are identical samples.

\begin{tabular}{|c|c|c|c|c|c|c|c|c|}
\hline Device & HIL & $\begin{array}{c}\text { Active layer } \\
\operatorname{DIP}(50 \mathrm{~nm}) / \mathrm{C}_{60}(50 \mathrm{~nm}, \mathrm{RT})\end{array}$ & Top contact & $V_{\mathrm{oc}}(\mathrm{V})$ & $j_{\mathrm{sc}}\left(\mathrm{mA} / \mathrm{cm}^{2}\right)$ & $\mathrm{FF}(\%)$ & $R_{\mathrm{S}}\left(\Omega \mathrm{cm}^{2}\right)$ & $\mathrm{n}$ \\
\hline \multicolumn{9}{|c|}{ Variation of substrate heating with PEDOT as HIL } \\
\hline A & PEDOT & $\operatorname{DIP}\left(100^{\circ} \mathrm{C}\right)$ & $\mathrm{BCP} / \mathrm{Al}$ & 0.91 & -3.5 & 62.8 & 4 & 2.0 \\
\hline B & PEDOT & $\mathrm{DIP}(\mathrm{RT})$ & $\mathrm{BCP} / \mathrm{Al}$ & 0.93 & -3.7 & 52.8 & 66 & 4.7 \\
\hline $\mathrm{C}$ & PEDOT preheated & $\mathrm{DIP}(\mathrm{RT})$ & $\mathrm{BCP} / \mathrm{Al}$ & 0.93 & -3.7 & 57.8 & 6 & 2.5 \\
\hline $\mathrm{D}$ & PEDOT & $\mathrm{DIP}\left(5 \mathrm{~nm}, 100^{\circ} \mathrm{C} / 45 \mathrm{~nm}, \mathrm{RT}\right)$ & $\mathrm{BCP} / \mathrm{Al}$ & 0.94 & -3.9 & 61.0 & 5 & 2.0 \\
\hline \multicolumn{9}{|c|}{ Variation of substrate heating with HIL1.3 as HIL } \\
\hline $\mathrm{E}$ & HIL1.3 & $\mathrm{DIP}(\mathrm{RT})$ & $\mathrm{BCP} / \mathrm{Al}$ & 0.94 & -4.2 & 64.2 & 3 & 1.7 \\
\hline \multicolumn{9}{|c|}{ Influence of DIP purity } \\
\hline $\mathrm{F}$ & PEDOT & $\operatorname{DIP}\left(100^{\circ} \mathrm{C}\right.$, batch 1$)$ & $\mathrm{BCP} / \mathrm{Al}$ & 0.92 & -3.8 & 70.4 & 2 & 1.8 \\
\hline G & PEDOT & DIP (RT, batch 1) & $\mathrm{BCP} / \mathrm{Al}$ & 0.94 & -3.75 & 67.1 & 133 & 1.4 \\
\hline $\mathrm{H}$ & PEDOT & $\operatorname{DIP}\left(100^{\circ} \mathrm{C}\right.$, batch 2$)$ & $\mathrm{BCP} / \mathrm{Al}$ & 0.91 & -3.7 & 61.4 & 5 & 2.5 \\
\hline I & PEDOT & DIP (RT, batch 2) & $\mathrm{BCP} / \mathrm{Al}$ & 0.93 & -3.7 & 51.9 & 385 & 3.9 \\
\hline \multicolumn{9}{|c|}{ Top contact variation with PEDOT as HIL } \\
\hline $\mathrm{J}$ & PEDOT & DIP (RT) & $\mathrm{BCP} / \mathrm{Sm} / \mathrm{Al}$ & 0.94 & -2.9 & 62.4 & 304 & 2.0 \\
\hline $\mathrm{K}$ & PEDOT & $\mathrm{DIP}(\mathrm{RT})$ & $\mathrm{Sm} / \mathrm{Al}$ & 0.94 & -2.9 & 65.9 & 590 & 1.6 \\
\hline $\mathrm{L}$ & PEDOT & DIP (RT) & $\mathrm{BCP} / \mathrm{Al}$ & 0.94 & -3.9 & 60.8 & 747 & 1.4 \\
\hline M & PEDOT & $\mathrm{DIP}(\mathrm{RT})$ & $\mathrm{Al}$ & 0.93 & -3.8 & 52.2 & 1807 & 1.5 \\
\hline \multicolumn{9}{|c|}{ Top contact variation with HIL1.3 as HIL } \\
\hline $\mathrm{N}$ & HIL1.3 & $\mathrm{DIP}(\mathrm{RT})$ & $\mathrm{BCP} / \mathrm{Sm} / \mathrm{Al}$ & 0.93 & -3.7 & 64.0 & 7 & 1.6 \\
\hline $\mathrm{O}$ & HIL1.3 & DIP (RT) & $\mathrm{Sm} / \mathrm{Al}$ & 0.93 & -3.2 & 69.5 & 7 & 1.6 \\
\hline $\mathrm{P}$ & HIL1.3 & $\mathrm{DIP}(\mathrm{RT})$ & $\mathrm{BCP} / \mathrm{Al}$ & 0.94 & -4.2 & 64.2 & 3 & 1.7 \\
\hline Q & HIL1.3 & DIP (RT) & $\mathrm{Al}$ & 0.94 & -3.7 & 64.2 & 9 & 2.3 \\
\hline
\end{tabular}

$\mathrm{HOMO}$ at the interface to PEDOT:PSS amounts to $0.55 \mathrm{eV}$ and $0.25 \mathrm{eV}$ in the case for unheated and heated PEDOT:PSS, respectively.

\section{Influence of hole injection layer}

In the previous section substrate heating was used to manipulate the work function of the PEDOT:PSS and thus to change the barrier height for hole injection into DIP. Alternatively, other PEDOT:PSS containing formulations can be used providing hole injection layers with different work functions. In addition to Clevios ${ }^{\mathrm{TM}}$ P AI4083 (designated as PEDOT:PSS) another commercially available modification is applied: Clevios ${ }^{\mathrm{TM}}$ HIL1.3 (designated as HIL1.3). UPS studies on HIL1.3/DIP predict a lower hole injection barrier in the case of HIL1.3, which is attributed to its higher work function compared to PEDOT:PSS, as reported recently. ${ }^{26}$

HIL1.3 was used as hole injection layer of a PHJ solar cell fabricated as described in Sec. II without substrate heating. The $j-V$ curve of the solar cell (device E) is shown in Fig. 2(b) and the photovoltaic parameters are included in Table I. The open circuit voltage is almost unchanged compared to the PEDOT:PSS devices. Concerning the injection currents in forward direction the cell comprising HIL1.3 as hole injection layer shows comparable currents in forward direction as sample A for heated PEDOT:PSS, which is reflected in a low series resistance of $3 \Omega \mathrm{cm}^{2}$. The surface of the DIP film grown on unheated HIL1.3 shows small spherical islands, similar to the topography with PEDOT:PSS as substrate (AFM image not shown here).
The schematic energy level structure for the HIL1.3/DIP interface is depicted in Fig. 5(c). The work function of pristine HIL1.3 $(\Phi=5.70 \mathrm{eV})$ is even higher than that of heated PEDOT:PSS, however, due to an interface dipole of $-0.8 \mathrm{eV}$ between HIL1.3 and DIP the effective work function of DIP covered HIL1.3 and DIP on heated PEDOT:PSS are virtually identical.

\section{Influence of DIP purity}

Work on copper-phthalocyanine based solar cells revealed that the purity of the organic small molecular weight material used as active layer in solar cells can strongly impact the fill factor and thus device efficiencies. ${ }^{41}$ To demonstrate the importance of material purity, we investigated the $j-V$ curves of heated and unheated PHJ solar cells comprising DIP of different source batches, all being twice purified by gradient sublimation. From a variety of batches, the best (named as batch 1) and worst (named as batch 2) are compared to each other in PHJ solar cells. Additionally, the effect of material purity on charge carrier mobility was studied in organic field-effect transistors.

Figure 2(c) displays the $j-V$ characteristics of the devices based on the standard PHJ stack with PEDOT:PSS as hole injection layer. Both DIP batches are tested with heated (devices F and $\mathrm{H}$ ) and unheated substrates (devices $\mathrm{G}$ and I), respectively. Within the measurement accuracy, all samples show similar values for $V_{\text {oc }}$ and $j_{\text {sc }}$. The most noticeable difference is the current in forward direction, which manifests in strongly varying series resistances, and-associated with 
(a)

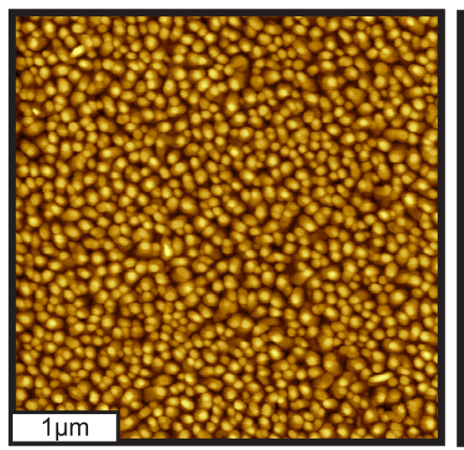

DIP $(50 \mathrm{~nm}, \mathrm{RT})$

(c)

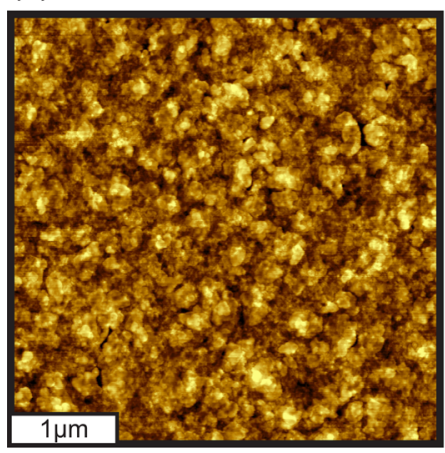

$\operatorname{DIP}\left(5 \mathrm{~nm}, 100^{\circ} \mathrm{C}\right)$ (b)

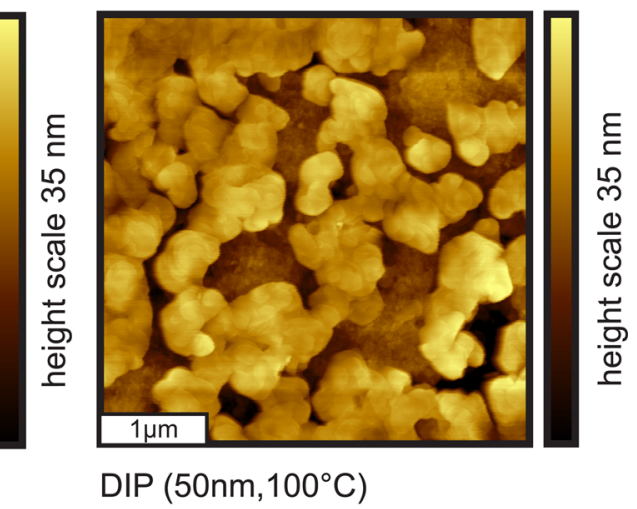

(d)
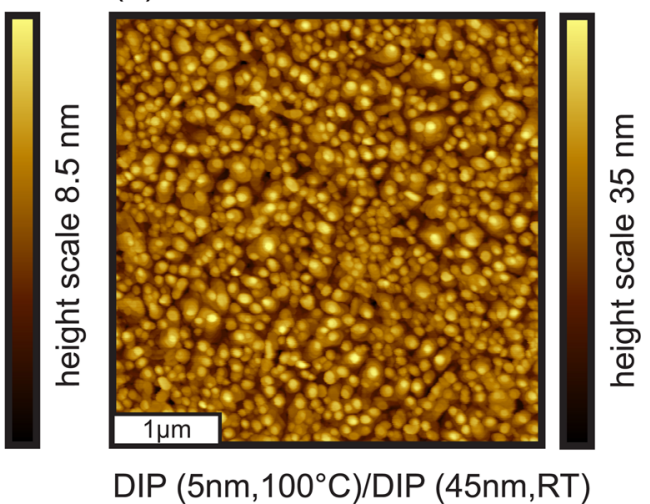

FIG. 3. (Color online) AFM image of (a) ITO/PEDOT:PSS/DIP $(50 \mathrm{~nm})$ on unheated substrate, (b) ITO/PEDOT:PSS/DIP (50 nm) evaporated at substrate temperature of $100^{\circ} \mathrm{C}$, (c) ITO/PEDOT:PSS/ DIP (5 nm, substrate temperature $100^{\circ} \mathrm{C}$ ), and (d) ITO/PEDOT:PSS/DIP (5 nm, substrate tempe rature $\left.100^{\circ} \mathrm{C}\right) / \mathrm{DIP}(45 \mathrm{~nm}, \mathrm{RT})$. The total image size is $4 \times 4 \mu \mathrm{m}^{2}$ in all cases. that-in different fill factors. In accordance with the results of the previous section, the devices with DIP evaporated on heated substrates show higher currents in forward direction. Thus, elevated substrate temperatures in combination with batch 1 of DIP (device $\mathrm{F}, R_{\mathrm{S}}=2 \Omega \mathrm{cm}^{2}$ ) results in excellent fill factors exceeding $70 \%$. In contrast, the unheated sample with batch 2 of DIP (sample I) has a high series resistance of $R_{\mathrm{S}}=385 \Omega \mathrm{cm}^{2}$, which affects the fill factor in a way that it reaches only $52 \%$. Figure 6 displays transfer characteristics of OFETs with top contacts of Ca and TTF-TCNQ for unipolar electron and hole transport, respectively. Charge carrier mobilities were determined by the transmission line method $^{22,42}$ using channel lengths between 50 and $150 \mu \mathrm{m}$. Figure 6(a) shows the hole transport regime (negative gate voltage) at a drain voltage of $V_{\mathrm{D}}=-2 \mathrm{~V}$ and Fig. 6(b) the electron transport regime (positive gate voltage) at a drain voltage of $V_{\mathrm{D}}=+2 \mathrm{~V}$, respectively. It was found that the values of the electron mobilities for the different DIP batches are similar with $\mu_{\mathrm{e}}($ DIP, batch 1$)=\mu_{\mathrm{e}}($ DIP, batch 2$)=1 \times 10^{-1} \mathrm{~cm}^{2} / \mathrm{Vs}$. In contrast, the hole mobilities differ considerably for the two DIP batches: $\mu_{\mathrm{h}}(\mathrm{DIP}$, batch 1$)=8 \times 10^{-2} \mathrm{~cm}^{2} /$ Vs and $\mu_{\mathrm{h}}(\mathrm{DIP}$, batch 2$)=5 \times 10^{-2} \mathrm{~cm}^{2} / \mathrm{Vs}$. It is important to note that this difference in mobility is clearly beyond the scattering of values obtained on nominally identical samples from different fabrication runs, which is less than $10 \%$ in our laboratory. Thus, we find that the performance of a DIP-C 60 PHJ solar cell is impacted by material's purity. Specifically, the fill factor increases with hole mobility, which is found in turn to depend on material purity.
To assess this quantity in more detail, mass spectrometry measurements of the different DIP batches were performed. The obtained spectra (see Fig. 7) are characterized by two major peaks at $\mathrm{m} / \mathrm{z}=400$ and 200 , corresponding to single and double ionized DIP molecules. Satellite peaks next to these ionization peaks are related to molecules containing carbon isotopes $(\mathrm{m} / \mathrm{z}=401$ and 402$)$ and measurement induced $\mathrm{H}_{2}$ split-offs $(m / z=394-398)$. Since the classification of distinctive impurities was not possible unambiguously, all other peaks detected in the mass spectra are considered as impurities. This includes both extrinsic, e.g., reactants of the chemical synthesis, and intrinsic by fragmentation of the pristine DIP molecules upon electron ionization. To obtain a rough measure for the purity level of the individual batches we compared the integrated areas of all impurity peaks occurring in the spectra normalized to the total amount of material detected. By this examination, batch 1 shows about half of the overall impurity content compared to batch 2 . However, as a general tendency two step gradient sublimation applied on the pristine DIP material reveals a high degree of purity for both batches as confirmed by the low background level in the mass spectra.

\section{Influence of top contact}

In Sec. IIIB we restricted our studies to the modification of the bottom contact of the solar cells. Now, variations of the top contact will be presented. We investigate the difference of $\mathrm{Sm}$ and $\mathrm{Al}$ as metal top contact and their interplay with the exciton blocking layer BCP. 


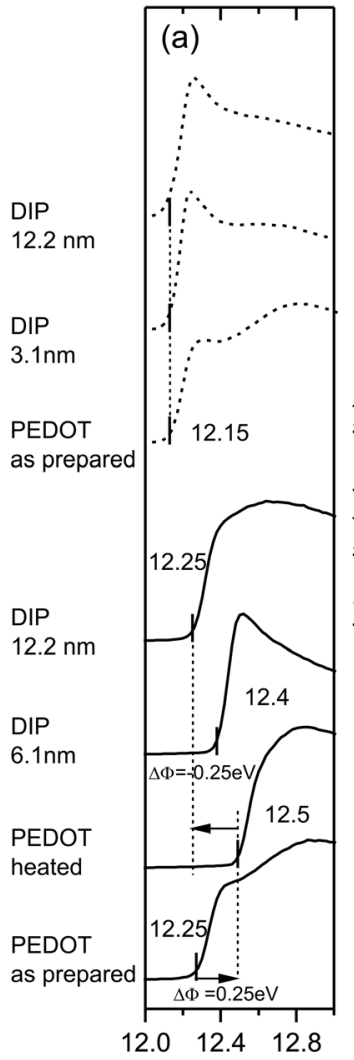

Kinetic Energy (eV)

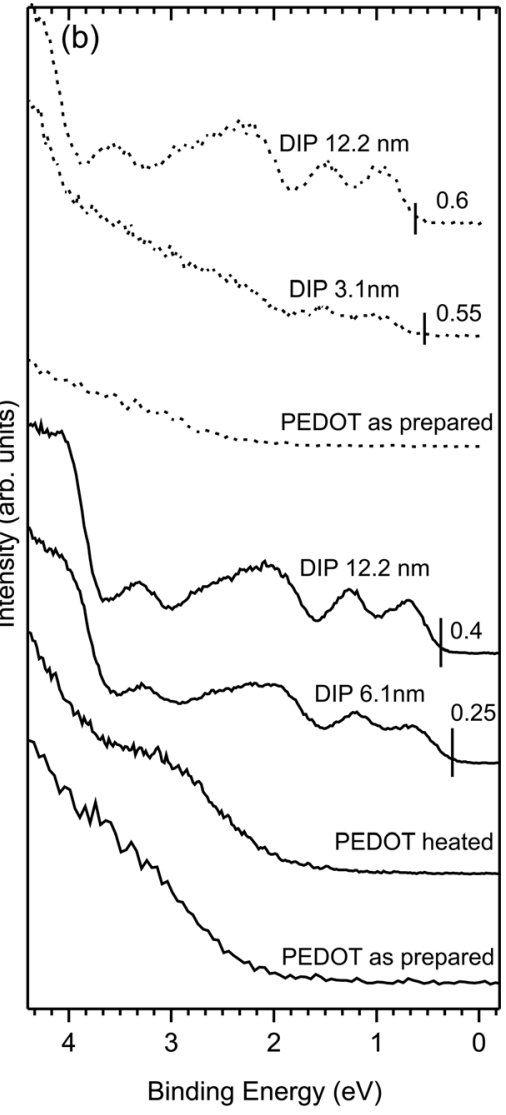

FIG. 4. Ultraviolet photoelectron spectra of heated (straight lines) and unheated (dashed lines) ITO/PEDOT:PSS substrates with different coverage of DIP. (a) Secondary electron cutoff (SECO) spectrum and (b) valence region spectrum.

It is known that thermal evaporation of metals on top of organic materials can lead to interdiffusion of metal atoms into the underlying layer and thus to formation of metal clusters inside the organic ${ }^{43,44}$ or cathode-induced damage for charge transport. ${ }^{45} \mathrm{DE}$ Castro et al. propose that isolated aluminum nanoclusters inside a $\mathrm{C}_{60}$ film, which are formed upon evaporation, lead to defect states close to the interface that modify the electric potential drop in the device and thus screen the electric field at the cathode for low forward bias. ${ }^{46}$ An established approach to prevent damage of the organic (a)

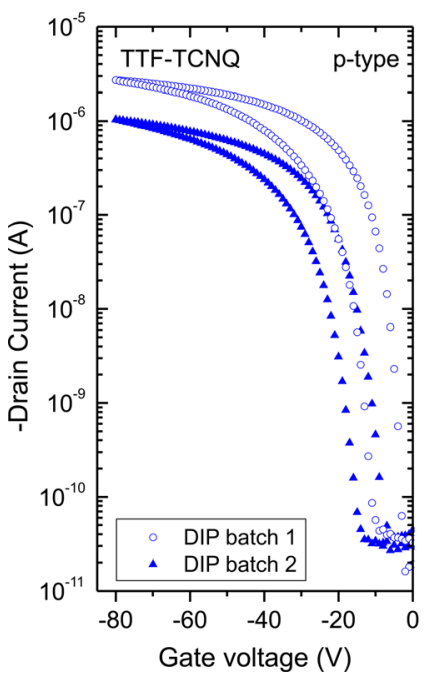

(b)

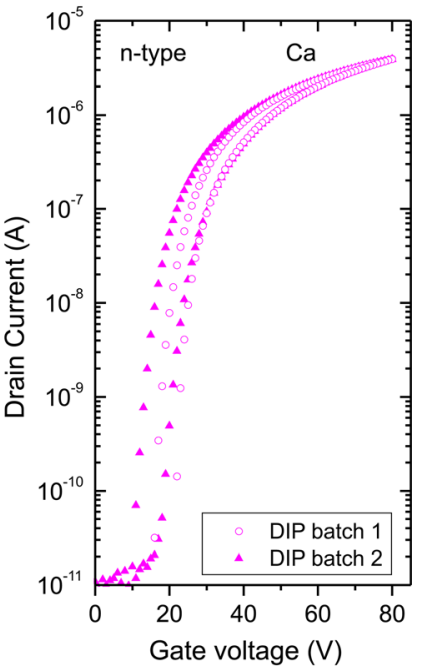

FIG. 6. (Color online) Transfer characteristics in the linear range for unipolar devices with different electrode materials (channel length $70 \mu \mathrm{m}$ ). (a) Hole transport regime (negative gate voltage) at a drain voltage of $V_{\mathrm{D}}=-2 \mathrm{~V}$ and (b) electron transport regime (positive gate voltage) at a given drain voltage of $V_{\mathrm{D}}=+2 \mathrm{~V}$. Each measurement consists of a forward-and backward voltage sweep, manifesting in a hysteresis, respectively.

material by cathode evaporation is the insertion of an exciton blocking layer (e.g., BCP). The beneficial effect of this interlayer on solar cell performance has been demonstrated by various studies, all describing its property to prohibit quenching of excitons at the electrode and to act as diffusion barrier for $\mathrm{Al}$ and as a protection layer to eliminate the creation of Al-induced defect states in $\mathrm{C}_{60}{ }^{47-50}$

To investigate the diffusion behavior of $\mathrm{Sm}$ into $\mathrm{C}_{60}$, thickness dependent UPS investigations were performed. Figures 8(a) and 8(b) show the UPS spectra of the interface between $\mathrm{Sm}$ and $\mathrm{C}_{60}$ with various steps of $\mathrm{Sm}$ thickness ranging from $\approx 1 \AA$ to $\approx 70 \AA$. The valence region spectra reveal a continuous decrease in intensity of the characteristic $\mathrm{C}_{60}$ features with increasing $\mathrm{Sm}$ coverage, suggesting the formation of a closed film already after a few monolayers.

In the following, studies of the protective effect of BCP are shown comprising the comparison between $\mathrm{Al}$ and $\mathrm{Sm}$ as cathode material with and without BCP. The $j-V$ curves of

(a)

unheated PEDOT:PSS

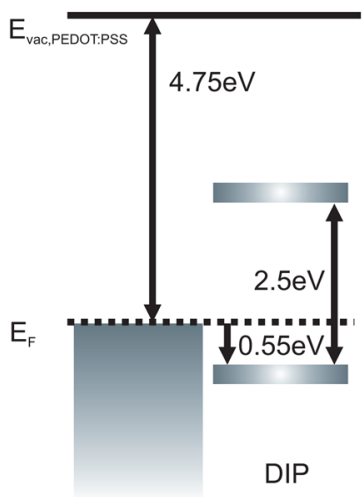

(b)

heated PEDOT:PSS

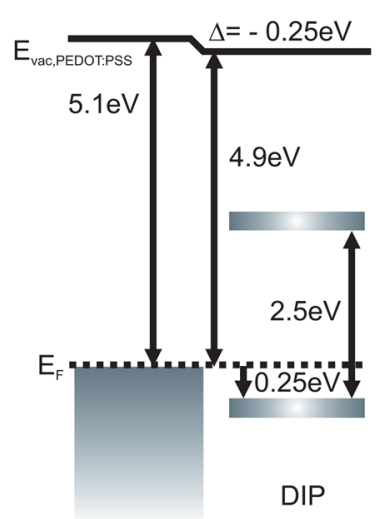

(c)

unheated HIL1.3

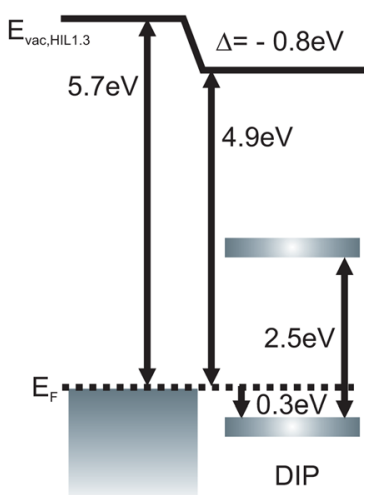

FIG. 5. (Color online) Schematic energy level diagrams for (a) DIP on unheated ITO/PEDOT:PSS and (b) on heated ITO/PEDOT:PSS, and (c) DIP on unheated ITO/HIL1.3. The transport gap of DIP is assumed to be $2.5 \mathrm{eV}$ (Ref. 60). 


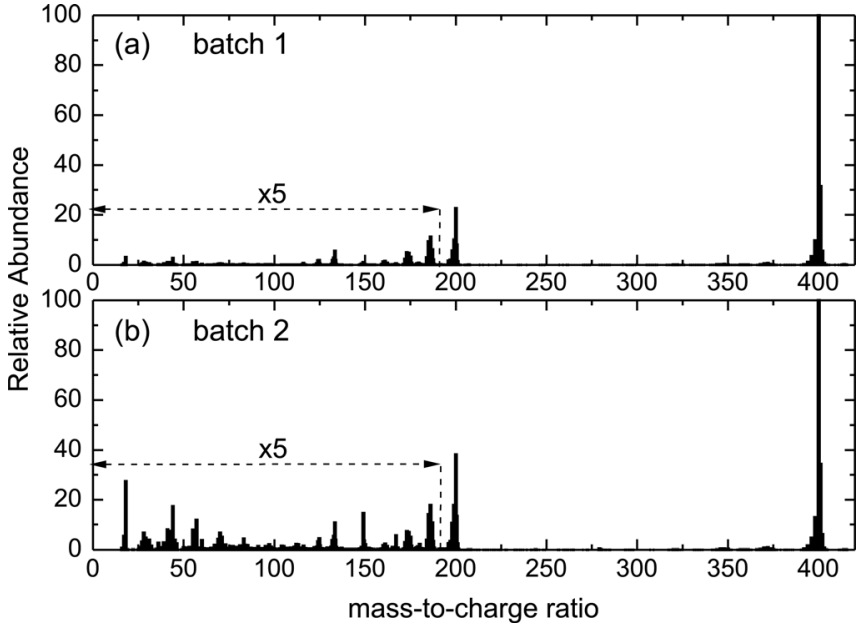

FIG. 7. Mass spectrometry measurements of two DIP batches. The range of $\mathrm{m} / \mathrm{z}$ between 0 and 190 was multiplied by a factor of 5 for better illustration of the impurity level.

the solar cells are shown in Fig. 9(a) for devices with PEDOT:PSS as hole injection layer, where the substrate was kept at room temperature during DIP evaporation. The photovoltaic parameters are included in Table I. Independent of the application of $\mathrm{BCP}$, the devices with $\mathrm{Sm}$ as top contact exhibit smaller values of $j_{\mathrm{SC}}$ than cells with pure Al. Optical transfer matrix calculations for the used device stack comprising a $\mathrm{Ca}(20 \mathrm{~nm}) / \mathrm{Al}(100 \mathrm{~nm})$ cathode predicts considerably lower photocurrents compared to a pure $\mathrm{Al}$ cathode. As Sm shows an even weaker metal reflectance, we expect similar tendencies as for the $\mathrm{Ca} / \mathrm{Al}$ cathode. Corresponding results can be found in Ref. 51, emphasizing the profound
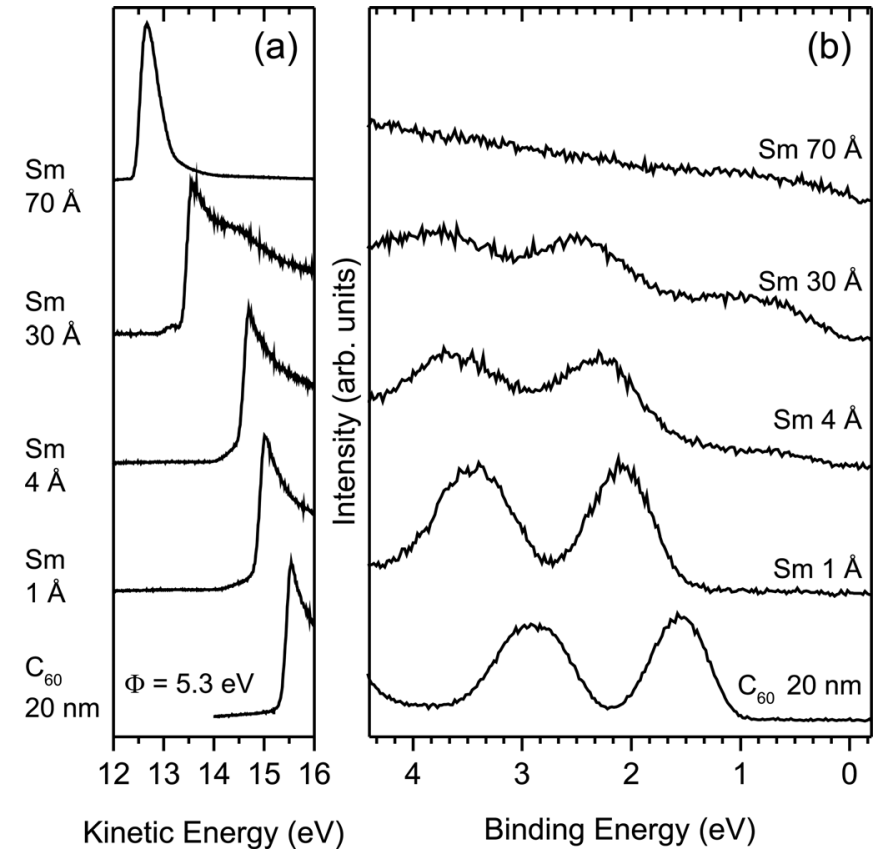

FIG. 8. Ultraviolet photoelectron spectra of ITO/HIL $1.3 / \mathrm{C}_{60}$ substrates with different coverage of Sm. (a) Secondary electron cutoff (SECO) spectrum and (b) valence region spectrum.

impact of the metal reflectivity on the electrical field confinement within multilayer device structures.

On the whole, the values for the series resistances extracted from the fits are comparatively high. Reasons can be found in the above discussed parameters like injection barrier from the unheated PEDOT:PSS or material purities. Nevertheless, devices with Sm as top contact show lower (a)

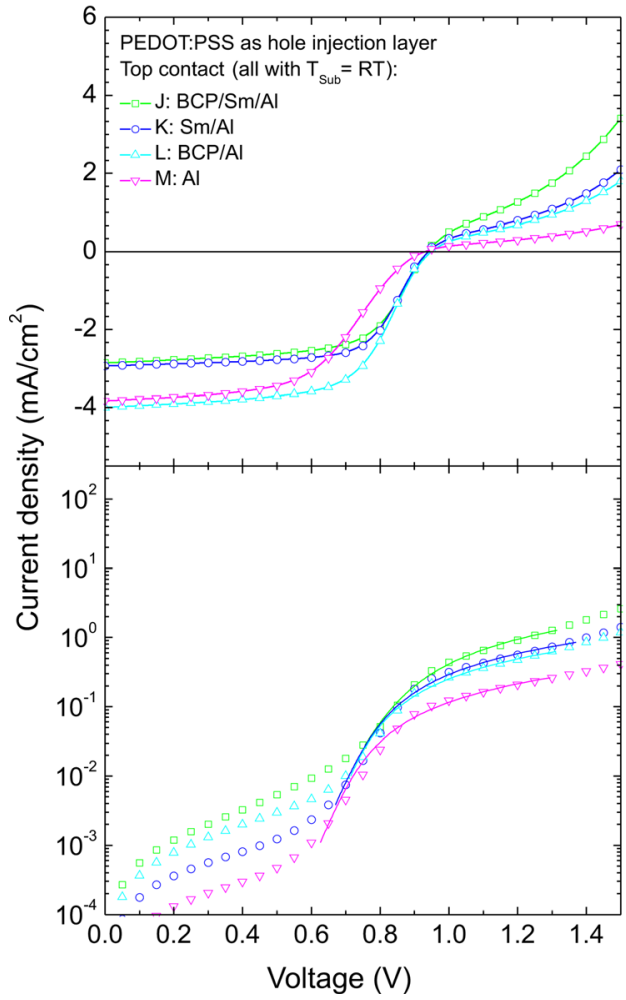

(b)

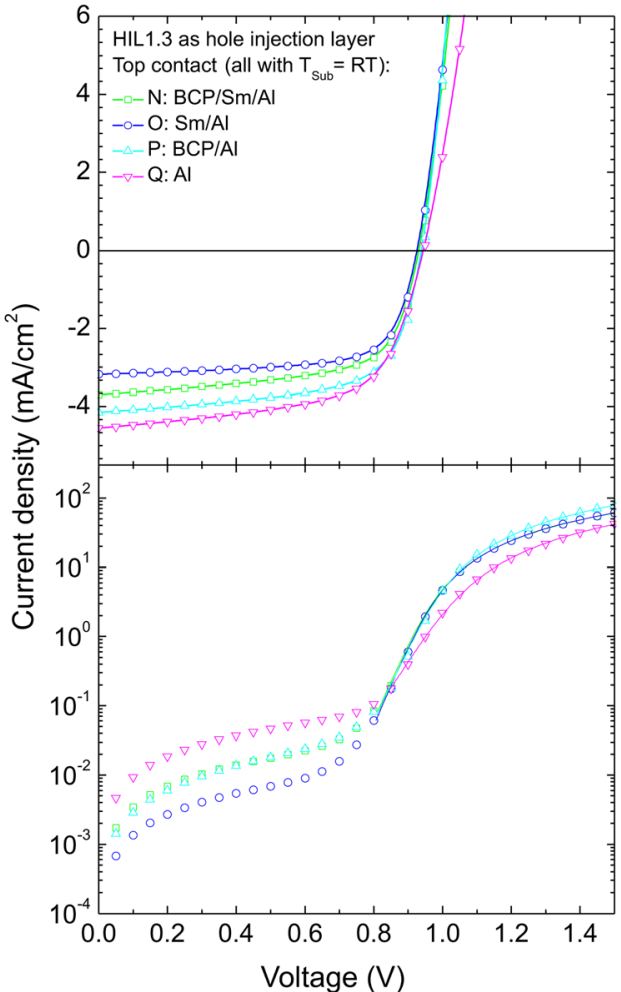

FIG. 9. (Color online) Current voltage characteristics of PHJ solar cells of the structure ITO/ (hole injection layer)/ $\operatorname{DIP}(50 \mathrm{~nm}) / \mathrm{C}_{60}(50 \mathrm{~nm}) /$ (top contact) cells with different top contacts, i.e., with and without $\mathrm{BCP}(5 \mathrm{~nm})$ and $\mathrm{Sm}$ (DIP evaporated at room temperature). (a) Devices J - M: PE- DOT:PSS as hole injection layer, (b) devices $\mathrm{N}-\mathrm{Q}$ : HIL1.3 as hole injection layer. Upper parts: $j-V$ characteristics under white LED illumination. Lower parts: Logarithmic plot of the dark $j-V$ characteristics (open symbols). The solid lines are fits based on the modified diode equation. Results of the fits are given in Table I. 
values for $R_{\mathrm{S}}$ than their counterparts with Al. The most striking variation in the series resistance is observed when $\mathrm{BCP}$ is inserted as interlayer underneath $\mathrm{Al}: R_{\mathrm{S}}$ is reduced by a factor of approx. 2.5 from $1807 \Omega \mathrm{cm}^{2}$ to $747 \Omega \mathrm{cm}^{2}$, whereas the ideality factor stays almost unchanged. This is reflected in an enhancement of the fill factor from $52 \%$ to $61 \%$.

Identical variations of the top contact were performed with HIL1.3 as hole injection layer. The $j$ - $V$ curves of the solar cells are shown in Fig. 9(b) (devices $\mathrm{N}-\mathrm{Q}$ ). The open circuit voltages are almost identical for all devices and the short circuit currents follow the same trend as with PEDOT:PSS as hole injection layer. In general, values for the series resistance are two orders of magnitude lower than the devices with PEDOT:PSS. Comparing the effect of BCP on the Al-devices (samples $\mathrm{P}$ and $\mathrm{Q}$ ), we find a reduction in $R_{\mathrm{S}}$ by a factor of three when inserting $\mathrm{BCP}$ as blocking layer. Even though the relative change is similar to the case with PEDOT:PSS as hole injection layer, there is no effect on the fill factor, which stays constant at a value of $\mathrm{FF}=64 \%$, indicating that it might be limited by other factors like material's purity in this case.

\section{DISCUSSION}

We have investigated different possible sources for s-shaped $j-V$ characteristics in $\mathrm{DIP} / \mathrm{C}_{60}$ planar heterojunction solar cells. It was found that the solar cell performance can be influenced by heating the substrate during evaporation of the donor material. ${ }^{26}$ The $j-V$ characteristics of devices where DIP was grown at room temperature are seriously affected by an s-shaped behavior, i.e., they show a decrease of the current close to the open-circuit voltage, which reduces the fill factor in a solar cell. By keeping the substrate temperature at $100^{\circ} \mathrm{C}$ during growth of DIP, dark currents in forward direction were increased, which is accompanied by improved fill factors and vanishing s-kinks in the current voltage characteristics. As mentioned above, these s-shapes are commonly ascribed to imbalances in charge carrier mobilities or energetic injection and extraction barriers between the photoactive layer system and the electrodes.

For devices where the substrate was heated before, during, or partly during the DIP evaporation we find an ideality factor of $n \approx 2-2.5$ and a series resistance of $R_{\mathrm{S}} \approx 4-6 \Omega$ $\mathrm{cm}^{2}$. Only for the completely unheated device $R_{\mathrm{S}}$ is increased by a factor of more than 10 , causing the concavity in the $j-V$ curve accompanied by a reduction in fill factor of approx. $20 \%$.

The fact that the series resistance mainly influences the fill factor coincides with theoretical predictions by Yoo et al:: They show that $j_{\mathrm{SC}}$ as well as $V_{\mathrm{oc}}$ are-up to a certain point-insensitive to $R_{\mathrm{S}}$, while the fill factor can be strongly affected. ${ }^{33}$ UPS measurements show that the work function of PEDOT:PSS is increased from $4.9 \mathrm{eV}$ to $5.1 \mathrm{eV}$ upon annealing. This coincides with the observation of Koch et al. clearly showing that an annealing step of PEDOT:PSS films spun-cast onto ITO leads to an increase of its work function. ${ }^{40}$ The deviation between the work functions of the unheated PEDOT:PSS films (cf. $4.75 \mathrm{eV}$ and $4.9 \mathrm{eV}$ ) might originate from slightly different storage conditions between substrate preparation and measurement, emphasizing that the work function of PEDOT:PSS is extremely sensitive to the precise preparation procedure as it depends critically on the residual water content in the conductive polymer film. In the case of unheated PEDOT:PSS the deposition of DIP does not change the sample work function, i.e., no interfacial dipole is formed, which gives an indication that energy level pinning of the DIP HOMO does not yet occur for this electrode work function. However, the interface energetics of heated PEDOT:PSS and DIP are different. Upon DIP deposition the sample work function changes from $5.1 \mathrm{eV}$ to $4.9 \mathrm{eV}$, due to an interface dipole. This observation is explained by pinning of the DIP HOMO level as a result of the high initial work function of heated PEDOT:PSS, leading to positive charge carriers in the DIP layer at the PEDOT:PSS/DIP contact.

The valence region spectra show that the low binding energy onset of the DIP HOMO at the interface to PEDOT:PSS amounts to $0.55 \mathrm{eV}$ and $0.25 \mathrm{eV}$ in the case of unheated and heated PEDOT:PSS, respectively. As this value corresponds to the hole injection barrier (HIB) at the anode-donor interface, we conclude that an additional annealing step of the PEDOT:PSS reduces the barrier for hole injection into the HOMO level of DIP and is thus responsible for the decrease in the series resistance of the solar cells whenever the substrate is heated in vacuum prior to the deposition of the donor. Adding up the sample work function and the low binding energy onset of the DIP HOMO for the $12.2 \mathrm{~nm}$ bulk film yields a DIP ionization energy of IE $\approx 5.3 \mathrm{eV} \pm 0.1 \mathrm{eV}$ for both cases, which is consistent with previously reported measurements. ${ }^{26}$

Comparing the $j$ - $V$ curves with the corresponding morphologies of the DIP films, it can be seen that the substrate heating before DIP evaporation or during the deposition of the DIP interlayer does not lead to a cohesive microstructure as found for elevated substrate temperatures. However, the solar cell characteristics are very similar to the cell where DIP was grown at $100^{\circ} \mathrm{C}$. Thus, it can be stated that the decisive role of substrate heating can be mostly attributed to a reduction of the hole injection barrier between the Fermi level of PEDOT:PSS and the HOMO level of the donor material DIP.

The usage of HIL1.3 as alternative hole injection layer instead of PEDOT:PSS leads to strongly enhanced currents in forward direction, accompanied by high fill factors, even though the substrate is kept at room temperature during DIP evaporation. The fact that the surface of the DIP film grown on unheated HIL1.3 shows small spherical islands, similar to the topography with unheated PEDOT:PSS as substrate, confirms the statement that the reduced series resistances in devices A, C, and D can be mainly ascribed to a lowering in hole injection barrier caused by heating up the PEDOT:PSS in vacuum. By contrast, the morphological changes-and with that changes in transport behavior inside the DIP bulk - seem to play a minor role in the series resistance of the solar cells. UPS measurements show that the high initial work function of HIL1.3 leads to pinning of the DIP HOMO level. ${ }^{40}$ The fact that the work function of multilayer DIP on all three hole injection layers is almost identical $(4.9 \mathrm{eV})$ 
confirms the statement given in earlier studies ${ }^{26}$ that this is the critical substrate work function for energy level pinning of the DIP HOMO. The valence region spectra (see Fig. 5 and supporting information of Ref. 26) reveal a hole injection barrier of $0.30 \mathrm{eV}$ at the HIL1.3/DIP interface, being similar to the value of heated PEDOT:PSS.

Giebink et al. proposed an alternative explanation for the occurrence of s-kinks. ${ }^{52}$ By means of a modified Shockley equation they successfully implemented specific properties of organic heterojunctions like polaron pair generation, recombination and dissociation, which are results of hopping transport and exciton binding energies being distinctive for organic semiconductors. Calculations show that small builtin potentials $\left(V_{\mathrm{bi}}\right)$ combined with large polaron pair recombination rates lead to concavities in the $j$ - $V$ curves. However, this kind of s-kink exclusively affects the fourth quadrant of the solar cell characteristics. Thus, we think that in our case a reduced $V_{\mathrm{bi}}$ - which is accompanied by a reduction of the anode work function-is not the decisive factor for the sshape. Furthermore, we can exclude misaligned transport levels of the exciton blocking layer $\mathrm{BCP}$ as reason for the skink $^{53}$ as we observed unhindered transport with $\mathrm{BCP} / \mathrm{Al}$ exclusively by heating the PEDOT:PSS. Instead, we attribute the s-shape of our current voltage curves, which is mainly affecting the current in the first quadrant, to the hole injection barrier at the anode/DIP interface.

Comparing the $j-V$ curves of the different DIP batches at room temperature and for heated PEDOT:PSS, the s-shapes observed for batch 1 are much less pronounced than those for batch 2. As a result, this leads to higher fill factors and enhanced overall efficiencies of the devices prepared of batch 1 . Mobility measurements of both batches studied by their application in OFETs result in similar values of the electron mobilities but considerably different hole mobilities for the two DIP batches. Therefore, we conclude that the device performance strongly correlates to the material's impurity levels estimated by mass spectroscopy. In these measurements, batch 1 contains about half of the integrated impurity content compared to batch 2 , though the total material purity of both batches is very high due to two step gradient sublimation. Additionally the lower hole mobility measured in the OFET transfer characteristics of batch 2 is a strong indication for impurity-induced hole trapping being also the reason for poor solar cell performance by the lower fill factor. For ultra-pure single crystalline reference systems, Probst et al. ${ }^{54}$ demonstrated a decrease of the hole mobility at room temperature by one order of magnitude in anthracene molecular crystals intentionally doped with tetracene at a relative concentration of only $10^{-7}$. Due to the respective HOMO level positions, tetracene acts as a bare electrical hole trap in the anthracene matrix. This illustrates that already very small amounts of impurities can strongly affect the charge transport characteristics and thereby increase the serial resistance of the studied DIP photovoltaic devices.

At the negative electrode, an ohmic contact to the electron acceptor is favorable, while the holes should be blocked. Brabec et al. stated that the interaction between $\mathrm{C}_{60}$ and many kinds of metal cathodes is large enough that Fermi level pinning of the $\mathrm{C}_{60}$ LUMO takes place for almost all common metal contacts. ${ }^{55}$ Regarding the values of the work function this condition seems to be fulfilled for both kinds of top contacts, due to their low values $\left(\Phi_{\mathrm{Al}} \approx 4.3 \mathrm{eV}\right.$ (Ref. 55) and $\Phi_{\mathrm{Sm}} \approx 2.7 \mathrm{eV}$ (Ref. 56)) compared to the LUMO level of the fullerene. However, vacuum deposition of metals does not lead to a well-defined interface between semiconductor and metal film. Penetration of metal atoms or clusters into the organic layer can change the effective work function of the metal compared to a free surface. Nevertheless, the differences in work function do not significantly influence the open circuit voltage, which is in accordance with the generally accepted theory that the open circuit voltage is mainly controlled by the energy-level offset at the donor-acceptor heterojunction ${ }^{57}$ and nearly invariant on electrodes with different work function values. ${ }^{58}$ Similar results have been obtained by Cheyns et al.: ${ }^{59}$ By means of an analytical model based on the continuity equation, they derive an expression for the open-circuit voltage for planar heterojunction solar cells. It indicates that $V_{\mathrm{oc}}$ does not depend on injection barriers and thus on the work functions of the metal contacts. However, extensions of their model show that the work function of the cathode metal leads to changes in the charge carrier concentration profile, which influences the shape of the $j$ - $V$ curve around $V_{\mathrm{oc}}$.

Studies on solar cells allow for a comparison of Sm or $\mathrm{Al}$ as metal top contact and their interplay with the exciton blocking layer BCP. With PEDOT:PSS as hole injection layer and the substrate kept at room temperature during DIP evaporation, the values for the series resistances extracted from the fits are comparatively high. Reasons can be found in the above discussed parameters like injection barrier from the PEDOT:PSS or material purity. Comparing the effect of $\mathrm{BCP}$, it can clearly be seen that there is no need for an exciton blocking layer when $\mathrm{Sm}$ is used as top contact, whereas its usage is indispensable for achieving high FFs with $\mathrm{Al}$ as metal cathode. UPS measurements (see Fig. 8) show that $\mathrm{Sm}$ - in contrast to $\mathrm{Al}$ - does not diffuse into $\mathrm{C}_{60}$ but, in fact, forms a closed film already after a few monolayers. This fact emphasizes the protective effect of BCP from metal penetration rather than its role as exciton diffusion barrier. Using HIL1.3 as hole injection layer, the series resistances are reduced by two orders of magnitude compared to the devices with PEDOT:PSS. Concerning the effect of $\mathrm{BCP}$ on the devices with pure $\mathrm{Al}$ cathode, there is no measurable influence on the FF, in spite of similar relative changes in $R_{\mathrm{S}}$. From this it can be stated that as long as the series resistance is comparatively low, changes in its value have only a minor effect on the fill factor.

\section{v. CONCLUSION}

In our studies we could figure out different interface and material-related aspects that influence the shape of the $j-V$ curve of planar heterojunction solar cells based on organic small molecules. The results show that high fill factors, and with that high power-conversion efficiencies, are only achievable if both energetic alignment at the electrodes and high purity of the active material are fulfilled. In particular, the series resistance $R_{\mathrm{S}}$ was used as a significant indicator 
describing the s-shape behavior. It was found that heating of the PEDOT:PSS film or the application of a hole injection layer with higher work function (HIL1.3) reduces the energetic barrier between the Fermi level $E_{\mathrm{F}}$ of the anode and the HOMO level of the donor material DIP. This reduction can be directly related to a lowering of $R_{\mathrm{S}}$ by a factor of 10 , concomitant to an increase of the fill factor by approx. $20 \%$. Similar tendencies were shown for different DIP material purities, which could be ascribed to an increase of the fill factor by up to $30 \%$ - observed independently of simultaneous substrate modification. A combined analysis of mobility measurements together with mass spectrometry give strong indication for impurity-induced hole trapping inside DIP. Variations in top contact configuration show that Samarium - in contrast to aluminum-does not penetrate into the organic layer underneath but, in fact, forms a closed film already after a few monolayers. In this case, an additional layer of BCP is not required to get high fill factors as opposed to aluminum. This approves the protective effect of the widely used exciton blocking layer $\mathrm{BCP}$ from metal penetration rather than its role as exciton diffusion barrier. Altogether, our studies emphasize that-independently of given values for $V_{\mathrm{oc}}$ and $j_{\mathrm{sc}}$ which are mainly determined by the chosen material combination-a careful consideration of both interface effects at the bottom and top contact as well as the photoactive semiconductor itself is indispensable to achieve highest possible fill factors - and with that highest possible power-conversion efficiencies.

\section{ACKNOWLEDGMENTS}

The authors acknowledge the German Research Foundation (DFG) for funding within the priority program SPP1355 and Heraeus Clevios for supplying HIL1.3. The photoemission studies at UVSOR were supported by the Joint Research Program (22-553) of IMS. We thank Tatsuhiko Nishi for technical support at the UVSOR and the Japan Society for the Promotion of Science (JSPS) for financing visits to Chiba.

${ }^{1}$ A. K. Ghosh and T. Feng, J. Appl. Phys. 44, 2781 (1973).

${ }^{2}$ C. W. Tang, Appl. Phys. Lett. 48, 183 (1986).

${ }^{3}$ M. A. Green, K. Emery, Y. Hishikawa, W. Warta, and E. D. Dunlop, Prog. Photovoltaics Res. Appl. 20, 12 (2012).

${ }^{4}$ R. Schueppel, K. Schmidt, C. Uhrich, K. Schulze, D. Wynands, J. L. Brédas, E. Brier, E. Reinold, H.-B. Bu, P. Baeuerle, B. Maennig, M. Pfeiffer, and K. Leo, Phys. Rev. B 77, 085311 (2008).

${ }^{5}$ M. Svensson, F. Zhang, S. Veenstra, W. Verhees, J. Hummelen, J. Kroon, O. Inganä, and M. Andersson, Adv. Mater. 15, 988 (2003).

${ }^{6}$ J. C. Bijleveld, R. A. M. Verstrijden, M. M. Wienk, and R. A. J. Janssen, Appl. Phys. Lett. 97, 073304 (2010).

${ }^{7}$ T. Kietzke, D. A. M. Egbe, H.-H. Hörhold, and D. Neher, Macromolecules 39, 4018 (2006).

${ }^{8}$ U. Hörmann, J. Wagner, M. Gruber, A. Opitz, and W. Brütting, Phys. Status Solidi RRL 5, 241 (2011).

${ }^{9}$ R. F. Bailey-Salzman, B. P. Rand, and S. R. Forrest, Appl. Phys. Lett. 91, 013508 (2007).

${ }^{10}$ F. Zhang, W. Mammo, L. M. Andersson, S. Admassie, M. R. Andersson, and O. Inganäs, Adv. Mater. 18, 2169 (2006).

${ }^{11}$ A. Kumar, S. Sista, and Y. Yang, J. Appl. Phys. 105, 094512 (2009).

${ }^{12}$ C. Uhrich, D. Wynands, S. Olthof, M. K. Riede, K. Leo, S. Sonntag, B. Maennig, and M. Pfeiffer, J. Appl. Phys. 104, 043107 (2008).

${ }^{13}$ K. Schulze, C. Uhrich, R. Schüppel, K. Leo, M. Pfeiffer, E. Brier, E. Reinold, and P. Bäuerle, Adv. Mater. 18, 2872 (2006).
${ }^{14}$ W. Tress, K. Leo, and M. Riede, Adv. Funct. Mater. 21, 2140 (2011).

${ }^{15}$ D. Gupta, S. Mukhopadhyay, and K. Narayan, Sol. Energy Mater. Sol. Cells 94, 1309 (2010)

${ }^{16}$ H. Jin, M. Tuomikoski, J. Hiltunen, P. Kopola, A. Maaninen, and F. Pino, J. Phys. Chem. C 113, 16807 (2009).

${ }^{17}$ M.-S. Kim, B.-G. Kim, and J. Kim, ACS Appl. Mater. Interfaces 1, 1264 (2009).

${ }^{18}$ J. Nelson, J. Kirkpatrick, and P. Ravirajan, Phys. Rev. B 69, 035337 (2004).

${ }^{19}$ L. M. Andersson, C. Müller, B. H. Badada, F. Zhang, U. Würfel, and O. Inganäs, J. Appl. Phys. 110, 024509 (2011).

${ }^{20}$ W. Tress, A. Petrich, M. Hummert, M. Hein, K. Leo, and M. Riede, Appl. Phys. Lett 98, 063301 (2011).

${ }^{21}$ A. K. Tripathi and J. Pflaum, Appl. Phys. Lett. 89, 082103 (2006).

${ }^{22}$ M. Horlet, M. Kraus, W. Brütting, and A. Opitz, Appl. Phys. Lett. 98, 233304 (2011).

${ }^{23}$ D. Kurrle and J. Pflaum, Appl. Phys. Lett. 92, 133306 (2008).

${ }^{24}$ A. C. Dürr, N. Koch, M. Kelsch, A. Rühm, J. Ghijsen, R. L. Johnson, J.-J. Pireaux, J. Schwartz, F. Schreiber, H. Dosch, and A. Kahn, Phys. Rev. B 68, 115428 (2003).

${ }^{25}$ S. Kowarik, A. Gerlach, S. Sellner, F. Schreiber, L. Cavalcanti, and O. Konovalov, Phys. Rev. Lett. 96, 125504 (2006).

${ }^{26}$ J. Wagner, M. Gruber, A. Hinderhofer, A. Wilke, B. Bröker, J. Frisch, P. Amsalem, A. Vollmer, A. Opitz, N. Koch, F. Schreiber, and W. Brütting, Adv. Funct. Mater. 20, 4295 (2010).

${ }^{27}$ A. Wilke, P. Amsalem, J. Frisch, B. Bröker, A. Vollmer, and N. Koch, Appl. Phys. Lett. 98, 123304 (2011).

${ }^{28}$ Product datasheet available at http://www.clevios.com.

${ }^{29} \mathrm{By}$ comparing to P3HT/PCBM cells measured under AM1.5G conditions, we estimate the LED illumination conditions to correspond roughly to 1 sun for the given cells. Please note that because of these deviations from standard illumination conditions power conversion efficiencies are not specified here.

${ }^{30}$ S. Ogawa, Y. Kimura, M. Niwano, and H. Ishii, Appl. Phys. Lett 90, 033504 (2007).

${ }^{31}$ M. Kraus, S. Richler, A. Opitz, W. Brütting, S. Haas, T. Hasegawa, A. Hinderhofer, and F. Schreiber, J. Appl. Phys. 107, 094503 (2010).

${ }^{32}$ S. Sze, Physics of Semiconductor Devices (Wiley, New York, 1982).

${ }^{33}$ S. Yoo, B. Domercq, and B. Kippelen, J. Appl. Phys. 97, 103706 (2005).

${ }^{34}$ M. D. Perez, C. Borek, S. R. Forrest, and M. E. Thompson, J. Am. Chem. Soc. 131, 9281 (2009).

${ }^{35}$ J. D. Servaites, S. Yeganeh, T. J. Marks, and M. A. Ratner, Adv. Funct. Mater. 20, 97 (2010).

${ }^{36}$ L. J. A. Koster, E. C. P. Smits, V. D. Mihailetchi, and P. W. M. Blom, Phys. Rev. B 72, 085205 (2005).

${ }^{37}$ T. Aernouts, W. Geens, J. Poortmans, P. Heremans, S. Borghs, and R. Mertens, Thin Solid Films 403-404, 297 (2002).

${ }^{38}$ S. Yoo, W. J. Potscavage, Jr., B. Domercq, S.-H. Han, T.-D. Li, S. C. Jones, R. Szoszkiewicz, D. Levi, E. Riedo, S. R. Marder, and B. Kippelen, Solid State Electron. 51, 1367 (2007).

${ }^{39}$ J. Xue, S. Uchida, B. P. Rand, and S. R. Forrest, Appl. Phys. Lett 84, 3013 (2004).

${ }^{40}$ N. Koch, ChemPhysChem 8, 1438 (2007).

${ }^{41}$ R. F. Salzman, J. Xue, B. P. Rand, A. Alexander, M. E. Thompson, and S. R. Forrest, Org. Electron. 6, 242 (2005).

${ }^{42}$ S. Luan and G. W. Neudeck, J. Appl. Phys. 72, 766 (1992).

${ }^{43}$ A. C. Dürr, F. Schreiber, M. Kelsch, and H. Dosch, Ultramicroscopy 98, 51 (2003).

${ }^{44}$ M. Scharnberg, J. Hu, J. Kanzow, K. Rätzke, R. Adelung, F. Faupel, C. Pannemann, U. Hilleringmann, S. Meyer, and J. Pflaum, Appl. Phys. Lett. 86, 024104 (2005).

${ }^{45}$ B. Rand, J. Li, J. Xue, R. Holmes, M. Thompson, and S. Forrest, Adv. Mater. 17, 2714 (2005).

${ }^{46}$ F. de Castro, J. Heier, F. Nüesch, and R. Hany, IEEE J. Sel. Top. Quant. 16, 1690 (2010).

${ }^{47}$ P. Peumans and S. R. Forrest, Appl. Phys. Lett. 79, 126 (2001).

${ }^{48}$ H. Gommans, B. Verreet, B. P. Rand, R. Muller, J. Poortmans, P. Heremans, and J. Genoe, Adv. Funct. Mater. 18, 3686 (2008).

${ }^{49}$ P. Peumans, V. Bulović, and S. R. Forrest, Appl. Phys. Lett. 76, 2650 (2000).

${ }^{50}$ N. Li, B. E. Lassiter, R. R. Lunt, G. Wei, and S. R. Forrest, Appl. Phys. Lett. 94, 023307 (2009).

${ }^{51}$ A. K. Pandey, P. E. Shaw, I. D. W. Samuel, and J.-M. Nunzi, 94, 103303 (2009). 
${ }^{52}$ N. C. Giebink, G. P. Wiederrecht, M. R. Wasielewski, and S. R. Forrest, Phys. Rev. B 82, 155305 (2010).

${ }^{53}$ C. K. Renshaw, C. W. Schlenker, M. E. Thompson, and S. R. Forrest, Phys. Rev. B 84, 045315 (2011).

${ }^{54}$ K. H. Probst and N. Karl, Phys. Status Solidi A 27, 499 (1975).

${ }^{55}$ C. J. Brabec, A. Cravino, D. Meissner, N. S. Sariciftci, T. Fromherz, M. T. Rispens, L. Sanchez, and J. C. Hummelen, Adv. Funct. Mater. 11, 374 (2001).

${ }^{56}$ N. Koch, J. Ghijsen, R. L. Johnson, J. Schwartz, J.-J. Pireaux, and A. Kahn, J. Phys. Chem. B 106, 4192 (2002).
${ }^{57}$ K. Vandewal, K. Tvingstedt, A. Gadisa, O. Inganäs, and J. V. Manca, Nature Mater. 8, 904 (2009).

${ }^{58}$ W. J. Potscavage, A. Sharma, and B. Kippelen, Acc. Chem. Res. 42, 1758 (2009).

${ }^{59}$ D. Cheyns, J. Poortmans, P. Heremans, C. Deibel, S. Verlaak, B. P. Rand, and J. Genoe, Phys. Rev. B 77, 165332 (2008).

${ }^{60}$ A. Opitz, J. Wagner, W. Brütting, I. Salzmann, N. Koch, J. Manara, J. Pflaum, A. Hinderhofer, and F. Schreiber, IEEE J. Sel. Top. Quant. 16, 1707 (2010) 